\title{
PULMONARY REHABILITATION USING MECHANICAL INSUFFLATION-EXSUFFLATION THERAPY FOR SPINAL CORD INJURY - TWO CASE STUDIES IN THE UNIVERSITY MALAYA MEDICAL CENTRE
}

\author{
Tan JH, Aishah A Fauzi, Hasnan N \\ Department of Rehabilitation Medicine, Faculty of Medicine, University of Malaya, 50603 Kuala Lumpur, MALAYSIA
}

Correspondence:

Aishah Ahmad Fauzi

Departmennt of Rehabilitation Medicine, Faculty of Medicine, University of Malaya, 50603 Kuala Lumpur, Malaysia

Email: aishahaf@ummc.edu.my

\begin{abstract}
There is a high incidence of $36 \%$ to $83 \%$ of respiratory dysfunction in patients with acute cervical spinal cord injury. Complications arising from respiratory dysfunction remain one of the most common causes of morbidity and mortality in the spinal cord injured population. Specialized pulmonary care and therapy can help individuals with tetraplegia to maintain a stable respiratory status allowing active participation in active rehabilitation. This would allow them to achieve rehabilitation goals of independent function and community reintegration. Mechanical insufflation-exsufflation (MIE) therapy is an option for secretion management in individuals with acute spinal cord injury. In this paper, we present our experience using MIE as an adjunct to management of secretions in the spinal cord injured population at the University of Malaya Medical Centre.
\end{abstract}

Keywords: Mechanical Insufflation-Exsufflation, Spinal Cord Injury, Respiratory Dysfunction

\section{Introduction}

Respiratory dysfunction is a major cause of morbidity and mortality in spinal cord injury (SCI) (1). Following SCl at the cervical and thoracic region, there is paralysis or weakness of the respiratory muscles with a reduction of vital capacity and lung and chest wall compliance. This results in breathing difficulties as well as an excessive effort during breathing. Patients will have an ineffective cough mechanism, which causes difficulty in the mobilisation of bronchial secretions (2). Secretion retention and autonomic dysfunction are additional factors that contribute to a worsening of respiratory status leading to a delay in access to other aspects of $\mathrm{SCl}$ focused rehabilitation.

The cough mechanism is an essential part in the removal of secretions. It has three components: an inspiratory phase, a compressive phase when the closure of the glottis together with the contraction of the expiratory muscles generates an increased intrathoracic pressure, and an expulsive phase resulting from the sudden opening of the glottis (3).The peak cough flow (PCF), a measure of the ability to produce a cough, can be used as an indicator of the effectiveness of secretion clearance from the airways. PCF can also be used to predict a potential failure in extubation or decannulation for patients with respiratory failure, who are receiving ventilation through an endotracheal tube or a tracheostomy(4).

Aggressive management of atelectasis and secretions are the cornerstones of treatment of respiratory dysfunction following acute $\mathrm{SCl}$ (5). Suctioning, manually assisted cough, percussion and postural drainage are methods commonly employed. Mechanical insufflation-exsufflation therapy (MIE) is a non-invasive method used as an adjunct intervention for secretion management of our patients with acute $\mathrm{SCl}$. With this method, insufflation with positive pressure is applied to the airway via a mechanical device, either through a tracheostomy or a mouthpiece. Immediately following this, an exsufflation with a negative pressure is then created in the airway, which generates an air flow similar to a cough (2).

MIE is not yet recognised as an essential step in standard guidelines for respiratory management for spinal cord injury of patients either in intensive care or a ward setting. We present reports of two patients with acute traumatic spinal cord injury with tetraplegia where MIE was successfully used as an adjunct to management of secretions, to illustrate the benefits of MIE. 


\section{Case 1}

A 42-year-old Chinese gentleman with no previous medical illness allegedly fell from a height of a one-storey building and sustained C5 fracture dislocation with a complete transection of the spinal cord, and a closed fracture of the distal end of the left radius. On presentation, he received $3 \mathrm{~L} /$ min of oxygen via nasal prongs. A posterior decompression with a lateral mass fusion of C3-C6 and an internal fixation of the radius were done. He had a neurological level of C5 AIS A. Post-operatively, there was difficulty in weaning him from the ventilator. This was further complicated by recurrent hospital-acquired infections. Despite undergoing bronchoscopy three times during his stay in the ICU, there were persistent consolidation and collapse of his right lung from mucus plugging. He required ventilator support for three months before he could be transferred out of the Intensive Care Unit (ICU) into the rehabilitation ward.

In ICU, he received chest physiotherapy, with chest percussions, deep breathing exercises and endotracheal suctioning on a twice-daily basis. He was also started on mucolytic agents. Manual assisted cough methods were taught to his caregiver. MIE therapy was started on a daily basis after a month in the ICU. He received 6-8 cycles with 20-30 seconds of rest in between cycles. He was gently and gradually started with a lower pressure regime of \pm 25 $\mathrm{cmH}_{2} \mathrm{O}$, which was gradually increased by $\pm 5 \mathrm{cmH}_{2} 0$ each week until he was able to tolerate pressures of $\pm 40 \mathrm{cmH}_{2} 0$. This regime was continued until six months following admission when he was finally weaned to room air. The effectiveness of respiratory management with MIE was monitored using Peak Cough Flow (PCF). Table 1 illustrated the charted PCF during his stay.

Table 1: Serial peak cough flow (PCF) readings during hospitalisation of the patient (case 1) in the inpatient rehabilitation ward.

\begin{tabular}{|l|c|c|}
\hline $\begin{array}{l}\text { Rehabilitation } \\
\text { stay }\end{array}$ & $\begin{array}{c}\text { PCF (Liter/ } \\
\text { min) pre MIE }\end{array}$ & $\begin{array}{c}\text { PCF (Liter/min) } \\
\text { post MIE }\end{array}$ \\
\hline $5^{\text {th }}$ month & 120 & 150 \\
\hline $6^{\text {th }}$ month & 160 & $180-190$ \\
\hline At discharge & 175 & $190-200$ \\
\hline
\end{tabular}

\section{Case 2}

A 51-year-old Chinese gentleman with underlying diabetes mellitus and hypertension was admitted for the removal of a C5-T2 intramedullary tumour. Post-operatively, he developed bilateral upper limb and lower limb weakness. He required prolonged ventilation and a tracheostomy was performed for him. His stay was further complicated by a cardiac event and hospital-acquired pneumonia. He was transferred to the rehabilitation ward, six weeks after the operation.

He was reviewed on a daily basis by the chest physiotherapist, and he received multiple therapies including inspiratory muscle exercises, manual assisted cough techniques, pharmacological intervention with nebulization of bronchodilators and mucolytic agents, and endotracheal suctioning. However, there was difficulty in weaning off oxygen support due to his thick and copious secretions. He was started on MIE therapy with daily 8-10 cycles, with 30-60 seconds in between cycles. Insufflation-exsufflation pressures were gradually increased on a weekly basis from $\pm 25 \mathrm{cmH}_{2} \mathrm{O}$, and after six weeks, he was able to tolerate pressures of $\pm 40 \mathrm{cmH}_{2} 0$. He tolerated MIE and was weaned off oxygen at the postoperative period of four months. Table 2 illustrated this patient's PCF readings during his stay.

Table 2: Serial peak cough flow (PCF) showing gradual improvement in PCF rates following combination of conventional chest and MIE therapy (case 2).

\begin{tabular}{|c|c|c|}
\hline Rehabilitation stay & $\begin{array}{c}\text { PCF (Liter/ min) } \\
\text { pre MIE }\end{array}$ & $\begin{array}{c}\text { PCF (liter/min) } \\
\text { post MIE }\end{array}$ \\
\hline Week 2 & 80 & 130 \\
\hline Week 4 & 85 & 110 \\
\hline Week 6 & 100 & 130 \\
\hline Week 8 & 100 & 150 \\
\hline Week 10 & 110 & 140 \\
\hline Week 12 & 125 & 170 \\
\hline Week 14 & 140 & 190 \\
\hline Week 16 & 150 & 180 \\
\hline
\end{tabular}

\section{Discussion}

Respiratory complications remain the leading cause of death in persons with spinal cord injury (SCI) (5). Development of respiratory failure is directly associated with the American Spinal Injury Association Impairment Scale (AIS) (1). It is well established that individuals with high cervical $\mathrm{SCl}$ (C1-C6) and complete injuries (AIS A) have a higher risk of developing respiratory complications of atelectasis, bronchospasm, pulmonary oedema and pneumonia $(1,5)$. Both of our patients had involvement of the high cervical spine region resulting in them having significant respiratory dysfunction. The difficulty in managing secretions and atelectasis would limit the participation of these patients in intensive $\mathrm{SCl}$ focused rehabilitation for mobility as well as functional training for activities of daily living. This problem can be partially circumvented by introducing an adjunct intervention for managing respiratory secretions such as mechanical insufflation-exsufflation therapy (MIE). It has been previously shown that tetraplegic patients, especially smokers, who were prescribed with outpatient MIE had fewer instances of hospitalisation for respiratory complications (2).

The magnitude of the PCF determines the effectiveness of mucus clearance (6). A PCF level is elicited by having the person cough as forcefully as possible through a peak flow meter. Depending on gender, height and age, a normal PCF 
reaches 6-12 litre / second or 360-720 L/ min. In patients with neuromuscular disorders and restrictive lung disease, a PCF of less than $160 \mathrm{~L} / \mathrm{min}$ can be used to predict a failed extubation or decannulation, which is likely due to inadequate clearance of bronchial secretions $(2,4)$. SCl patients with tetraplegia may have problems with secretion clearance similar to patients with neuromuscular disorders due to weak inspiratory and expiratory muscles. PCF was chosen as an objective outcome measure to assess the efficacy of the MIE therapy. Once both patients achieved a PCF of more than $160 \mathrm{~L} / \mathrm{min}$, rehabilitation goals were achieved, and they were able to be discharged from the inpatient rehabilitation facility without oxygen therapy. A consensus regarding the target PCF in patients with spinal cord injury has not yet been reached given the lack of data.

There is a paucity of strong evidence of the benefits of MIE in the SCI population. Studies on the use of MIE in patients with neuromuscular disease indicate that MIE therapy produces a greater increase in PCF compared to other standard cough augmentation techniques $(3,4)$. PCF produced during MIE significantly exceeds that produced by manually assisted coughing (6). MIE therapy also results in significant increase in forced vital capacity (FVC) and forced expiratory volume in 1 second $\left(\mathrm{FEV}_{1}\right)(7)$. However, insufflation-exsufflation pressures of less than $\pm 35 \mathrm{cmH}_{2} \mathrm{O}$ appear to be inadequate to produce a PCF of $160 \mathrm{~L} / \mathrm{min}$ (8). Both our patients showed improvement of their PCF following their tolerance of $\pm 30-40 \mathrm{~cm} \mathrm{H}_{2} \mathrm{O}$ of insufflationexsufflation pressure.

A study using the visual analogue scale (VAS) looking at patient comfort and distress found that MIE therapy was tolerated as well as the other cough augmentation techniques (4).The need for deep suctioning is reduced, and it is more comfortable for patients. As MIE treatment is well tolerated and has been shown to be efficient in secretion management in spinal cord injury, it should be considered as an adjunct therapy for patients in acute rehabilitation facilities when pulmonary problems become significant.

Our two case reports illustrated the benefits of adding MIE therapy to standard respiratory care following acute spinal cord injury. Robust studies are needed to prove the effectiveness of MIE in the SCI population.

\section{Conclusion}

The use of MIE as an adjunct to other therapeutic measures can improve PCF values and help in the management of clearing of secretion in the respiratory care in individuals with spinal cord injury. Good secretion management reduces respiratory complications and may improve the general condition of patients with $\mathrm{SCl}$. This may lead to a shortened weaning of the tracheostomy, allowing patients to increase their participation in other aspects of rehabilitation, and reducing the length of hospitalisation. MIE therapy should be considered in acute rehabilitation facilities treating individuals with $\mathrm{SCl}$.

\section{Acknowledgements}

We would like to thank the patients whom we reviewed in this report.

\section{References}

1. Wong SL, Shem K, Crew J. Specialized respiratory management for acute cervical spinal cord injury:: a retrospective analysis. Top Spinal Cord Inj Rehabil. 2012;18(4):283-90.

2. Crew JD, Svircev JN, Burns SP. Mechanical insufflationexsufflation device prescription for outpatients with tetraplegia. J Spinal Cord Med. 2010;33(2):128-34.

3. Sivasothy P, Brown L, Smith IE, Shneerson JM. Effect of manually assisted cough and mechanical insufflation on cough flow of normal subjects, patients with chronic obstructive pulmonary disease (COPD), and patients with respiratory muscle weakness. Thorax. 2001;56(6):438-44.

4. Chatwin M, Ross E, Hart N, Nickol AH, Polkey MI, Simonds AK. Cough augmentation with mechanical insufflation/exsufflation in patients with neuromuscular weakness. Eur Respir J. 2003;21(3):502-8.

5. Berlly M, Shem K. Respiratory management during the first five days after spinal cord injury. J Spinal Cord Med. 2007;30(4):309-18.

6. Bach JR. Mechanical insufflation-exsufflation. Comparison of peak expiratory flows with manually assisted and unassisted coughing techniques. Chest. 1993;104(5):1553-62.

7. Pillastrini P, Bordini S, Bazzocchi G, Belloni G, Menarini M. Study of the effectiveness of bronchial clearance in subjects with upper spinal cord injuries: an examination of a rehabilitation programme involving mechanical insufflation and exsufflation. Spinal cord. 2006;44(10):614-6.

8. Gomez-Merino E, Sancho J, Marin J, Servera E, Blasco ML, Belda FJ, et al. Mechanical insufflationexsufflation: pressure, volume, and flow relationships and the adequacy of the manufacturer's guidelines. Am J Phys Med Rehabil. 2002;81(8):579-83. 